\title{
Association of brain-derived neurotrophic factor and nerve growth factor gene polymorphisms with susceptibility to migraine
}

This article was published in the following Dove Press journal:

Neuropsychiatric Disease and Treatment

19 July 2016

Number of times this article has been viewed

\author{
Salih Coskun' \\ Sefer Varol ${ }^{2}$ \\ Hasan $\mathrm{H}$ Ozdemir ${ }^{2}$ \\ Elif Agacayak ${ }^{3}$ \\ Birsen Aydın ${ }^{4}$ \\ Oktay Kapan ${ }^{5}$ \\ Mehmet Akif Camkurt ${ }^{6}$ \\ Saban Tunc ${ }^{7}$ \\ Mehmet Ugur Cevik² \\ 'Department of Medical Genetics, \\ ${ }^{2}$ Department of Neurology, \\ ${ }^{3}$ Department of Obstetrics and \\ Gynecology, Medical Faculty, Dicle \\ University, Diyarbakır, Turkey; \\ ${ }^{4}$ Department of Neurology, Diyarbakır \\ Education and Research Hospital, \\ Diyarbakır, Turkey; ${ }^{5}$ Department of \\ Neurology, Elazığ Education and \\ Research Hospital, Elazığ, Turkey; \\ ${ }^{6}$ Department of Psychiatry, Afsin State \\ Hospital, Kahramanmaras, Turkey; \\ ${ }^{7}$ Laboratory of Molecular Genetics, \\ Medical Faculty, Dicle University, \\ Diyarbakır, Turkey
}

Correspondence: Salih Coskun

Department of Medical Genetics, Dicle Üniversitesi, Tıp Fakültesi, Tıbbi Genetik AD, 2 I 280, Sur/Diyarbakır, Turkey

Tel +90412248800 I

Fax +90 4I 2488440

Email scoskun9@gmail.com
Abstract: Migraine is one of the most common neurological diseases worldwide. Migraine pathophysiology is very complex. Genetic factors play a major role in migraine. Neurotrophic factors, such as brain-derived neurotrophic factor (BDNF) and nerve growth factor (NGF), play an important role in central nervous system functioning, development, and modulation of pain. This study investigates whether polymorphisms in the BDNF and $N G F$ genes are associated with migraine disease in a Turkish case-control population. Overall, 576 subjects were investigated (288 patients with migraine and 288 healthy controls) for the following polymorphisms: rs6265(G/A), rs8192466(C/T), rs925946(G/T), rs2049046(A/T), and rs12273363(T/C) in the $B D N F$ gene, and rs6330(C/T), rs11466112(C/T), rs11102930(C/A), and rs4839435(G/A) in the $N G F$ gene using $5^{\prime}$-exonuclease allelic discrimination assays. We found no differences in frequency of the analyzed eight polymorphisms between migraine and control groups. However, the frequency of minor A alleles of rs6265 in BDNF gene was borderline significant in the patients compared with the healthy controls $(P=0.049$; odds ratios [ORs] [95\% confidence intervals $\{\mathrm{CIs}\}]=0.723[0.523-0.999])$. Moreover, when the migraine patients were divided into two subgroups, migraine with aura (MA) and migraine without aura (MO), the minor TT genotype of rs6330 in $N G F$ was significantly higher in MA patients than in MO patients ( $P=0.036)$ or healthy controls $(P=0.026)$, and this disappeared after correction for multiple testing. Also, the rs6330*T minor allele was more common in the MA group than in the MO group or controls $(P=0.011$, ORs [95\% CIs] $=1.626$ [1.117-2.365] or $P=0.007$, ORs [95\% CIs] $=1.610$ [1.140-2.274], respectively). In conclusion, this is the first clinical study to evaluate the association between $B D N F$ and $N G F$ polymorphisms in migraine patients compared with health controls. Our findings suggest that the $N G F$ rs $6330^{*} \mathrm{~T}$ minor allele might be nominated as a risk factor for developing aura in migraine disease. Our results should be considered as preliminary, and they need to be confirmed by future studies.

Keywords: migraine, brain-derived neurotrophic factor, nerve growth factor, polymorphism, aura, migraine with aura, headache

\section{Introduction}

Migraine is a common, disabling neurological disorder that affects up to $12 \%$ of the world's population. ${ }^{1}$ Migraine starts in childhood and affects quality of life for many years. ${ }^{2,3}$ Two main types of migraine, migraine with aura (MA) and migraine without aura (MO), have been defined by the International Headache Society. ${ }^{4}$ The pathophysiological mechanisms that underlie migraine are complex and not yet fully clarified. Advances in technology have informed us about the significance to migraine of events such as cortical spreading depression (CSD) and activation of the 
trigeminovascular system and its constituent neuropeptides, as well as the importance of neuronal and glial ion channels and transporters that contribute to the putative cortical excitatory/inhibitory imbalance that renders migraineurs susceptible to an attack. ${ }^{5}$ On the other hand, although several compounds (eg, calcitonin gene-related peptide, sex hormone metabolism, glutamate, and serotonin) have been implicated in migraine pathophysiology, our understanding of the biochemistry of migraine is still limited. ${ }^{5-7}$

Neurotrophic factors, such as the brain-derived neurotrophic factor $(B D N F)$ and nerve growth factor $(N G F)$, are now emerging as important modulators of nociceptive function in adulthood. ${ }^{8} B D N F$ is expressed in nociceptive sensory neurons and transported anterogradely to the dorsal horn of the spinal cord, where it is located in dense core vesicles in C-fiber terminals. ${ }^{8}$ It is the most common neurotrophin and has an important role in synaptic plasticity, neurogenesis, neural growth, and differentiation. ${ }^{9}$ Several studies pointed to the specific role of the BDNF system in migraine. Martins et al reported that a strong support for decreased serum $B D N F$ levels in chronic migraine patients. ${ }^{10}$ Migraineurs have also been found to have a significant decrease in levels of $B D N F$ in platelets compared with controls. ${ }^{11}$ In addition, the $B D N F$ transcripts for polymorphism have been linked with migraine in an Australian population. ${ }^{12}$ However, BNDF polymorphisms in Turkish populations have not yet been evaluated.

$N G F$ is widely expressed in the limbic system of the central nervous system and is thought to be involved in mood and cognition. ${ }^{13}$ It plays an important role in neuronal survival, neuroplasticity, and learning, which is essential for responding to stress. ${ }^{14}$ Also, it is known to be released by several cell types in response to tissue inflammation, and it induces hyperalgesia. ${ }^{15}$ On the other hand, peripheral $N G F$ is thought to contribute to the sensitization of nociceptors. Blandini et $\mathrm{al}^{11}$ showed that a reduction of platelet $N G F$ was observed in migraine sufferers.

Recently, there has been increased interest into the possible association between gene polymorphisms and the risk for migraine. The $B D N F$ and $N G F$ gene single-nucleotide polymorphisms (SNPs) have been associated with a number of neuropsychiatric disorders. ${ }^{16-20}$ Moreover, while a few studies found no evidence of the rs6265 polymorphism in $B D N F$ being associated with migraine susceptibility, the rs2049046 in the $B D N F$ gene was observed as being associated with migraine. ${ }^{12,21,22}$ However, no data are available for $N G F$ gene polymorphisms in migraine disease. We hypothesized that polymorphisms in the BDNF and $N G F$ genes may contribute to susceptibility to migraine disease. The aims of this study were 1) to further explore a possible role of $B D N F$ gene polymorphisms in migraine susceptibility in a Turkish population and 2) to study, for the first time, $N G F$ as a candidate gene. Therefore, in the present study, we investigated nine polymorphisms in the BDNF and $N G F$ genes in an adult Turkish population with migraine with/ without aura and healthy controls.

\section{Materials and methods Study samples}

We included two main groups as study and control groups in the present study. The study group consisted of 288 unselected and unrelated patients with migraine. All migraine patients, who were registered at the outpatient clinic of the Department of Neurology at Dicle University Medical Faculty and Diyarbakır Education and Research Hospital in Diyarbakır, Turkey, between January 2014 and January 2016, were included in this study. Migraine was diagnosed according to the International Headache Society criteria. ${ }^{4}$ Patients with obesity (body mass index $>30 \mathrm{~kg} / \mathrm{m}^{2}$ ), diabetes, and other neurologic or psychiatric disorders were excluded from this study. The control group consisted of 288 healthy volunteers who applied to the other outpatient clinics at Dicle University. A complete medical history was recorded, and they were examined. The controls were unrelated to the patients, and they had no clinical evidence of migraine, no history of migraine, and no family history of migraine or other neurological and psychiatric diseases. In addition, they had no history of diabetes mellitus, hypertension, obesity (body mass index $>30 \mathrm{~kg} / \mathrm{m}^{2}$ ), or organic or genetic disorders. The mean age, sex, and ethnicity of the control group were matched with the study group. All participants were of Turkish origin, from the same geographical area (southeastern region of Turkey), particularly around Diyarbakır. The migraine patients were assigned to two subgroups, MA and MO. This case-control study was approved by the Ethics Committee of Dicle University, Medical Faculty, and each subject provided written informed consent.

\section{DNA isolation and genotyping}

Whole-blood samples $(200 \mu \mathrm{L})$ were taken into ethylenediaminetetraacetic acid-treated tubes, and genomic DNA was isolated using a commercially available kit according to the manufacturer's instructions (QIAamp DNA Mini Kit, Qiagen, Hilden, Germany). The DNA concentration was determined using a NanoDrop spectrophotometer (Thermo Fisher Scientific, Waltham, MA, USA), and samples were 
stored at $-20^{\circ} \mathrm{C}$ until a polymerase chain reaction (PCR) was performed. In total, nine SNPs within the $N G F$ and $B D N F$ genes were selected based on their functionality, according to the National Center of Biotechnology Information databases (www.ncbi.nlm.nih.gov/projects/SNP/), the International HapMap Project database (www.hapmap.org), and a review of the literature for neuropsychiatric disorders. ${ }^{12,16,18-22}$ Genotyping was carried out using Taq-Man 5'-exonuclease allelic discrimination assays (Thermo Fisher Scientific) and the StepOnePlus Real-Time PCR system (Thermo Fisher Scientific) for the following variants: rs6265(G/A), rs8192466(C/T), rs925946(G/T), rs2049046(A/T), and rs $12273363(\mathrm{~T} / \mathrm{C})$ in the $B D N F$ gene, and rs6330(C/T), rs11466112(C/T), rs11102930(C/A), and rs4839435(G/A) in the $N G F$ gene. PCR conditions were $60^{\circ} \mathrm{C}$ for 30 seconds and $95^{\circ} \mathrm{C}$ for 10 minutes, followed by 40 cycles of 15 seconds at $95^{\circ} \mathrm{C}$ for and 1 minute at $60^{\circ} \mathrm{C}$. Finally, $60^{\circ} \mathrm{C}$ for 30 seconds was applied for post-PCR reading. The fluorescent signal was detected at the pre-PCR, amplification (at the end of each cycle), and post-PCR reading steps.

\section{Statistical analysis}

The distributions of the genotype and polymorphism between migraine and control groups were compared by using chisquare $\left(\chi^{2}\right)$ or Fisher exact tests. For the age variable, which is a continuous value, the normality test was conducted using the Kolmogorov-Smirnov test. The age variable was compared between the two groups using Student's $t$-test. Two-tailed tests were used unless otherwise stated. The goodness of fit $\chi^{2}$ test was used to assess deviations from the Hardy-Weinberg equilibrium in the control group. The data were given as mean \pm standard deviation or frequency. A $P$-value of less than 0.05 was considered to show a statistically significant result. Bonferroni corrections were applied to each test to adjust for multiple testing. Since the $B D N F$ and $N G F$ polymorphisms have three genotypes, the Bonferroni corrections were made for each of the three tests conducted, with the significance criterion of $P<0.017(P=0.05 / 3)$. Odds ratios (ORs) and 95\% confidence intervals (CIs) were also calculated. Statistical analyses were performed with SPSS 15.0 (SPSS Inc., Chicago, IL, USA).

\section{Power analysis}

For tests used in allele and genotype analysis, post hoc computation of the achieved power of the sample was calculated with $\mathrm{G}^{*}$ Power software, version 3.1.9 (HeinrichHeine-Universität, Düsseldorf, Germany). ${ }^{23}$ With the current sample size, the achieved power of the study was between
0.66 and 0.78 for the $d f=2\left(\chi^{2}=7.242\right)$ and $d f=1\left(\chi^{2}=7.382\right)$ tests, respectively.

\section{Results}

\section{Clinical characteristics of the subjects}

The study group consisted of 288 subjects (137 males, 151 females) with a mean age of $31.26 \pm 10.28$ years, and the control group consisted of 288 healthy subjects (133 males, 155 females) with a mean age of $31.53 \pm 8.92$ years. There was no significant difference in age or sex between the groups ( $P=0.729, P=0.738$, respectively). In addition, the number of patients who had MA was $112(38.9 \%)$, and the number who had MO was 176 (61.1\%). The demographic characteristics of the groups are listed in Table 1.

\section{Comparison of the genotype and allele distributions}

The genotype distributions of four SNPs in the $B D N F$ gene and three SNPs in the NGF gene in the controls and in the patients followed Hardy-Weinberg equilibrium (Table 2). The allelic and genotypic distributions of the analyzed SNPs are listed in Tables 3 and 4. No significant difference in genotypic and allelic distribution was observed in these SNPs in the $B D N F$ and $N G F$ genes between migraine patients and healthy controls. However, the allelic distribution of rs6265 in the $B D N F$ gene showed a borderline significant difference between migraine cases and healthy controls ( $P=0.049$; ORs $[95 \% \mathrm{CIs}]=0.723[0.523-0.999])$. In the migraine patients, $100(17.4 \%)$ had the minor A allele and $476(82.6 \%)$ had the $\mathrm{G}$ allele; in the control subjects, $76(13.2 \%)$ had the A allele and $500(86.8 \%)$ had the $\mathrm{G}$ allele for the $B D N F$ rs 6265 polymorphism. The frequency of the minor A allele of rs6265 was higher in the patients compared with the healthy controls.

Migraine patients were divided into two subgroups: the first group was the MA group $(n=112)$ and the second group was the MO group ( $\mathrm{n}=176)$. A significant association

Table I Demographic characteristics of study participants

\begin{tabular}{llll}
\hline Parameters & $\begin{array}{l}\text { Migraine } \\
\text { patients } \\
(\mathbf{n = 2 8 8 )}\end{array}$ & $\begin{array}{l}\text { Healthy } \\
\text { controls } \\
(\mathbf{n = 2 8 8})\end{array}$ & P-value \\
\hline $\begin{array}{l}\text { Age, years (mean } \pm \text { SD) } \\
\text { Sex }\end{array}$ & $31.26 \pm 10.28$ & $31.53 \pm 8.92$ & 0.729 \\
$\quad \begin{array}{l}\text { Female n, (\%) } \\
\text { Male n, (\%) }\end{array}$ & $151(52.4)$ & $155(53.8)$ & 0.738 \\
$\begin{array}{l}\text { Migraine types } \\
\text { MA n, (\%) }\end{array}$ & $137(47.6)$ & $133(46.2)$ & \\
MO n, (\%) & $112(38.9)$ & & \\
\hline
\end{tabular}

Abbreviations: MA, migraine with aura; $M O$, migraine without aura; SD, standard deviation. 
Table 2 Hardy-Weinberg law in studied SNPs in the groups

\begin{tabular}{|c|c|c|c|c|c|}
\hline \multirow[t]{2}{*}{ Gene } & \multirow[t]{2}{*}{ SNP } & \multicolumn{2}{|c|}{ Migraine patients } & \multicolumn{2}{|c|}{ Healthy controls } \\
\hline & & $\chi^{2}$ & $P$-value & $\chi^{2}$ & $P$-value \\
\hline \multirow[t]{4}{*}{ BDNF } & rs6265 & 0.078 & 0.779 & 0.001 & 0.994 \\
\hline & rs925946 & 0.062 & 0.803 & 0.497 & $0.48 I$ \\
\hline & rs2049046 & 0.151 & 0.697 & 3.544 & 0.059 \\
\hline & rs 12273363 & I.07| & 0.301 & 0.237 & 0.626 \\
\hline \multirow[t]{3}{*}{ NGF } & rs6330 & 0.326 & 0.568 & 0.249 & 0.617 \\
\hline & rsIII02930 & 0.921 & 0.337 & 0.143 & 0.704 \\
\hline & rs4839435 & 0.299 & 0.584 & 0.109 & $0.74 I$ \\
\hline
\end{tabular}

Abbreviations: $\chi^{2}$, chi-square; SNP, single-nucleotide polymorphism.

was detected between $N G F$ rs6330 polymorphism and aura. A total of 90 MA patients and $172 \mathrm{MO}$ patients were successfully genotyped for rs6330 polymorphism. Regarding the rs6330 polymorphism, 32 (35.6\%) were identified with the CC genotype, $41(45.6 \%)$ with the CT genotype, and $17(18.9 \%)$ with the rare TT genotype from patients with MA. Among the 172 subjects in the MO group, 83 (48.3\%) were identified with the CC genotype, 73 (42.4\%) with the CT genotype, and 16 (9.3\%) with the rare TT genotype. The rare TT genotype of rs6330 was significantly higher in the patients with aura compared to the patients without aura $\left(\chi^{2}=6.613, d f=2, P=0.036\right)$. However, the significance was not maintained after Bonferroni adjustment $(P<0.017)$. In the analysis of allele distributions, the frequency of the $\mathrm{C}$ allele was 105 (58.3\%) and 239 (69.5\%) in the MA and MO groups, respectively. The frequency of the rare T allele was 75 (41.7\%) and 105 (30.5\%) in the MA and MO groups, respectively. A significant difference in allele frequencies of rs6330 polymorphism was observed between the MA and MO groups $\left(\chi^{2}=6.506, P=0.011\right.$, ORs $[95 \%$ CIs $]=1.626$ [1.117-2.365]). The rare $\mathrm{T}$ allele was more frequent in the MA group. It was shown that migraine patients with the $\mathrm{T}$ allele had a 1.62-fold higher risk of developing aura (ORs [95\% CIs] $=1.626$ [1.117-2.365]). Furthermore, we compared the differences between the MA group and healthy

Table 3 Distribution of the genotype and allele of SNPs in BDNF and NGF genes in all groups

\begin{tabular}{|c|c|c|c|c|c|c|c|c|}
\hline \multirow{2}{*}{$\begin{array}{l}\text { Gene } \\
B D N F\end{array}$} & \multirow{2}{*}{$\begin{array}{l}\text { rs number } \\
\text { rs6265(G/A) }\end{array}$} & \multirow[t]{2}{*}{ Group } & \multirow[t]{2}{*}{$\mathbf{N}$} & \multicolumn{3}{|c|}{ Genotypes (N, freq) } & \multicolumn{2}{|c|}{ Alleles ( $\mathbf{N}$, freq) } \\
\hline & & & & GG & GA & $\mathrm{AA}$ & $\mathrm{G}$ & A \\
\hline & & Migraine & 288 & $196(0.681)$ & $84(0.292)$ & $8(0.028)$ & $476(0.826)$ & $100(0.174)$ \\
\hline & & MA & 112 & $75(0.670)$ & $35(0.312)$ & $2(0.018)$ & $185(0.826)$ & $39(0.174)$ \\
\hline & & MO & 176 & $121(0.688)$ & $49(0.278)$ & $6(0.034)$ & $291(0.827)$ & $61(0.173)$ \\
\hline & & $\mathrm{HC}$ & 288 & $217(0.753)$ & $66(0.229)$ & $5(0.017)$ & $500(0.868)$ & $76(0.132)$ \\
\hline \multirow[t]{5}{*}{ BDNF } & rs925946(G/T) & & & GG & GT & TT & $\mathrm{G}$ & $\mathrm{T}$ \\
\hline & & Migraine & 288 & $183(0.635)$ & $94(0.326)$ & II (0.038) & $460(0.799)$ & $116(0.201)$ \\
\hline & & MA & 112 & $68(0.607)$ & $4 \mathrm{I}(0.366)$ & $3(0.027)$ & $177(0.790)$ & $47(0.210)$ \\
\hline & & MO & 176 & $115(0.653)$ & $53(0.301)$ & $8(0.045)$ & $283(0.804)$ & $69(0.196)$ \\
\hline & & $\mathrm{HC}$ & 288 & $174(0.604)$ & $97(0.337)$ & $17(0.059)$ & $445(0.773)$ & $131(0.227)$ \\
\hline \multirow[t]{5}{*}{ BDNF } & rs2049046(A/T) & & & AA & AT & $\mathrm{TT}$ & A & $\mathrm{T}$ \\
\hline & & Migraine & 288 & $64(0.222)$ & $147(0.510)$ & $77(0.267)$ & $275(0.477)$ & $30 \mathrm{I}(0.523)$ \\
\hline & & MA & 112 & $26(0.232)$ & $60(0.536)$ & $26(0.232)$ & $112(0.500)$ & $\mathrm{II} 2(0.500)$ \\
\hline & & MO & 176 & $38(0.216)$ & $87(0.494)$ & $5 \mathrm{I}(0.290)$ & $163(0.463)$ & $189(0.537)$ \\
\hline & & $\mathrm{HC}$ & 288 & $82(0.285)$ & $128(0.444)$ & $78(0.27 I)$ & $292(0.507)$ & $284(0.493)$ \\
\hline \multirow[t]{5}{*}{ BDNF } & rs $12273363(\mathrm{~T} / \mathrm{C})$ & & & $\mathrm{TT}$ & $\mathrm{TC}$ & $\mathrm{CC}$ & $\mathrm{T}$ & C \\
\hline & & Migraine & 288 & $224(0.778)$ & $62(0.215)$ & $2(0.007)$ & $510(0.885)$ & $66(0.115)$ \\
\hline & & $\mathrm{MA}$ & 112 & $84(0.750)$ & $28(0.250)$ & $0(0.000)$ & $196(0.875)$ & $28(0.125)$ \\
\hline & & MO & 176 & I $40(0.795)$ & $34(0.193)$ & $2(0.011)$ & $314(0.892)$ & $38(0.108)$ \\
\hline & & $\mathrm{HC}$ & 288 & $212(0.736)$ & $69(0.240)$ & $7(0.024)$ & $493(0.856)$ & $83(0.144)$ \\
\hline \multirow[t]{5}{*}{ NGF } & $\mathrm{rs} 6330(\mathrm{C} / \mathrm{T})$ & & & CC & CT & TT & C & $\mathrm{T}$ \\
\hline & & Migraine & 262 & 115 (0.439) & I I 4 (0.435) & $33(0.126)$ & $344(0.656)$ & $180(0.344)$ \\
\hline & & $\mathrm{MA}$ & 90 & $32(0.356)$ & $4 \mathrm{I}(0.456)$ & $17(0.189)$ & $105(0.583)$ & $75(0.417)$ \\
\hline & & MO & 172 & $83(0.483)$ & $73(0.424)$ & $16(0.093)$ & $239(0.695)$ & $105(0.305)$ \\
\hline & & $\mathrm{HC}$ & 288 & $140(0.486)$ & $119(0.413)$ & $29(0.101)$ & $399(0.693)$ & $177(0.307)$ \\
\hline \multirow[t]{5}{*}{ NGF } & rsll $102930(C / A)$ & & & $\mathrm{CC}$ & $\mathrm{CA}$ & AA & C & A \\
\hline & & Migraine & 281 & $75(0.267)$ & I 48 (0.527) & $58(0.206)$ & $298(0.530)$ & $264(0.470)$ \\
\hline & & $\mathrm{MA}$ & 107 & $31(0.290)$ & $53(0.495)$ & $23(0.215)$ & $115(0.537)$ & $99(0.463)$ \\
\hline & & MO & 174 & $44(0.253)$ & $95(0.546)$ & $35(0.201)$ & $183(0.526)$ & $165(0.474)$ \\
\hline & & $\mathrm{HC}$ & 288 & $76(0.264)$ & $147(0.510)$ & $65(0.226)$ & $299(0.519)$ & $277(0.48 I)$ \\
\hline \multirow[t]{5}{*}{ NGF } & rs4839435(G/A) & & & GG & GA & AA & G & A \\
\hline & & Migraine & 288 & $270(0.938)$ & $18(0.062)$ & $0(0.0)$ & $558(0.969)$ & $18(0.031)$ \\
\hline & & MA & 112 & $105(0.938)$ & $7(0.062)$ & $0(0.0)$ & $217(0.969)$ & $7(0.03 \mathrm{I})$ \\
\hline & & MO & 176 & $165(0.938)$ & II $(0.062)$ & $0(0.0)$ & $34 I(0.969)$ & $\mathrm{II}(0.03 \mathrm{I})$ \\
\hline & & $\mathrm{HC}$ & 288 & $277(0.962)$ & II (0.038) & $0(0.0)$ & $565(0.98 I)$ & II (0.019) \\
\hline
\end{tabular}

Abbreviations: BDNF, brain-derived neurotrophic factor; freq, frequency; HC, healthy control; MA, migraine with aura; MO, migraine without aura; NGF, nerve growth factor; SNP, single-nucleotide polymorphism. 
Table 4 Chi-square analysis of the allelic and genotypic frequencies in all migraine groups and controls for all studied SNPs

\begin{tabular}{|c|c|c|c|c|c|c|c|}
\hline \multirow[t]{2}{*}{ Subjects } & \multicolumn{3}{|c|}{ Genotypes } & \multicolumn{4}{|c|}{ Alleles } \\
\hline & $x^{2}$ & $d f$ & $P$-value & $x^{2}$ & $d f$ & $P$-value & ORs (95\% Cls) \\
\hline \multicolumn{8}{|l|}{ BDNF rs6265 } \\
\hline Migraine vs HC & 3.920 & 2 & 0.141 & 3.862 & I & 0.049 & $0.723(0.523-0.999)$ \\
\hline $\mathrm{MA}$ vs $\mathrm{HC}$ & 2.995 & 2 & 0.223 & 2.329 & I & 0.127 & $0.72 \mid$ (0.473-I.099) \\
\hline $\mathrm{MO}$ vs $\mathrm{HC}$ & 3.011 & 2 & 0.221 & 2.968 & 1 & 0.085 & $0.725(0.502-1.046)$ \\
\hline MA vs MO & 0.954 & 2 & 0.621 & 0.001 & I & 0.980 & $1.006(0.646-1.565)$ \\
\hline \multicolumn{8}{|l|}{ BDNF rs 925946} \\
\hline Migraine vs $\mathrm{HC}$ & 1.559 & 2 & 0.458 & 1.159 & I & $0.28 \mathrm{I}$ & I.I $67(0.88 \mathrm{I}-\mathrm{I} .547)$ \\
\hline $\mathrm{MA}$ vs $\mathrm{HC}$ & 1.877 & 2 & 0.391 & 0.289 & I & 0.591 & I. $108(0.76 \mathrm{I}-1.6 \mathrm{I} 4)$ \\
\hline $\mathrm{MO}$ vs $\mathrm{HC}$ & 1.228 & 2 & $0.54 I$ & 1.275 & 1 & 0.259 & I.207 (0.870-I.675) \\
\hline MA vs MO & 1.739 & 2 & 0.419 & 0.162 & I & 0.687 & $1.089(0.7$ I $8-1.650)$ \\
\hline \multicolumn{8}{|l|}{ BDNF rs2049046 } \\
\hline Migraine vs HC & 3.538 & 2 & 0.170 & 1.003 & I & 0.316 & I.I $25(0.893-1.4$ I8) \\
\hline $\mathrm{MA}$ vs $\mathrm{HC}$ & 2.719 & 2 & 0.256 & 0.031 & I & 0.859 & $1.028(0.755-1.399)$ \\
\hline $\mathrm{MO}$ vs $\mathrm{HC}$ & 2.727 & 2 & 0.255 & 1.683 & I & 0.194 & I.192 (0.9|4-I.555) \\
\hline MA vs MO & 1.161 & 2 & 0.559 & 0.748 & I & 0.387 & I.I59 (0.829-I.62I) \\
\hline \multicolumn{8}{|l|}{ BDNF rs I 2273363} \\
\hline Migraine vs HC & 3.482 & 2 & 0.175 & 2.227 & I & 0.135 & $0.768(0.544-1.086)$ \\
\hline MA vs $\mathrm{HC}$ & 2.779 & 2 & 0.249 & 0.492 & I & 0.483 & $0.848(0.536-1.343)$ \\
\hline $\mathrm{MO}$ vs $\mathrm{HC}$ & 2.510 & 2 & 0.285 & 2.517 & I & 0.113 & $0.719(0.477-1.082)$ \\
\hline MA vs MO & $2.48 I$ & 2 & 0.289 & 0.392 & 1 & 0.531 & $0.847(0.504-1.424)$ \\
\hline \multicolumn{8}{|l|}{ NGF rs6330 } \\
\hline Migraine vs $\mathrm{HC}$ & 1.591 & 2 & 0.451 & 1.642 & I & 0.200 & $1.179(0.916-1.518)$ \\
\hline MA vs $\mathrm{HC}$ & 7.242 & 2 & $0.026^{a}$ & 7.382 & 1 & 0.007 & $1.610(1.140-2.274)$ \\
\hline $\mathrm{MO}$ vs $\mathrm{HC}$ & 0.100 & 2 & 0.951 & 0.004 & 1 & 0.948 & $0.990(0.74 I-1.323)$ \\
\hline MA vs MO & 6.613 & 2 & $0.036^{a}$ & 6.506 & 1 & 0.011 & $1.626(1.117-2.365)$ \\
\hline \multicolumn{8}{|l|}{ NGF rsIII 02930} \\
\hline Migraine vs HC & 0.322 & 2 & $0.85 I$ & 0.141 & I & 0.706 & $1.045(0.829-1.319)$ \\
\hline $\mathrm{MA}$ vs $\mathrm{HC}$ & 0.267 & 2 & 0.874 & 0.209 & I & 0.647 & I.076 (0.785-I.473) \\
\hline $\mathrm{MO}$ vs $\mathrm{HC}$ & 0.614 & 2 & 0.735 & 0.039 & I & 0.842 & $\mathrm{I} .027(0.787-\mathrm{I} .34 \mathrm{I})$ \\
\hline MA vs MO & 0.721 & 2 & 0.697 & 0.071 & I & 0.790 & $0.954(0.678-1.343)$ \\
\hline \multicolumn{8}{|l|}{ NGF rs4839435 } \\
\hline Migraine vs $\mathrm{HC}$ & 1.779 & I & 0.182 & 1.733 & 1 & 0.188 & $\mathrm{I} .657(0.775-3.539)$ \\
\hline $\mathrm{MA}$ vs $\mathrm{HC}$ & 1.108 & I & 0.292 & 1.083 & I & 0.298 & $1.657(0.634-4.329)$ \\
\hline $\mathrm{MO}$ vs $\mathrm{HC}$ & 1.429 & I & 0.232 & 1.394 & I & 0.237 & I.657 (0.7II-3.863) \\
\hline MA vs MO & 0.000 & 1 & 1.000 & 0.000 & 1 & 1.000 & $1.000(0.382-2.619)$ \\
\hline
\end{tabular}

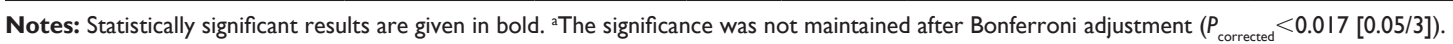

Abbreviations: BDNF, brain-derived neurotrophic factor; $\chi^{2}$, chi-square; $d f$, degrees of freedom; $\mathrm{HC}$, healthy control; MA, migraine with aura; $M O$, migraine without aura; NGF, nerve growth factor; ORs ( $95 \% \mathrm{Cls})$, odds ratios ( $95 \%$ confidence intervals); SNPs, single-nucleotide polymorphisms.

controls in all analyzed polymorphisms, and only the rs6330 variant was observed to be significantly associated with MA for both allelic $\left(\chi^{2}=7.382, P=0.007\right)$ and genotypic $\left(\chi^{2}=7.242\right.$, $P=0.026$ ) frequency distributions (Tables 3 and 4 ). However, the significance was not maintained after Bonferroni adjustment in the genotype distribution of rs63330. Meanwhile, the $\mathrm{T}$ allele of rs6330 was more frequent in patients with aura than in healthy subjects $(P=0.007$, ORs $[95 \% \mathrm{CIs}]=1.610$ [1.140-2.274]), suggesting an association with increased susceptibility to aura in migraine patients. Additionally, there was no statistically significant difference between MO and healthy controls for the genotype and allele distributions of all studied polymorphisms. On the other hand, only the $\mathrm{CC}$ genotype was observed in all patients and controls for the
$B D N F$ rs8192466(C/T) and $N G F$ rs11466112(C/T) polymorphisms, while the CT and TT genotypes were not observed in all participants.

\section{Discussion}

In this study, the relationship between migraine disease and polymorphisms in the $B D N F$ and $N G F$ genes was investigated in migraine patients and healthy controls. The functional $B D N F$ rs6265 (p.Val66Met) polymorphism has a borderline association with migraine in the Turkish population. Also, we found a significant association between $N G F$ rs6330 polymorphism and aura.

The $B D N F$ concentrations and the various polymorphisms in the $B D N F$ gene have been associated with a wide 
array of diseases and conditions, reflecting their involvement in neuronal function. A few studies have previously evaluated associations between $B D N F$ and developing migraine risk. The studies have reported that migraine patients have elevated $B D N F$ levels in serum during migraine attacks ${ }^{24}$ or decreased $B D N F$ levels in platelets, possibly attributable to platelet activation during migraine attacks with immediate release of $B D N F$ when compared with healthy controls. ${ }^{11}$ To date, three studies have investigated whether the various $B D N F$ polymorphisms, including rs6265, are related to migraine risk. Marziniak et $\mathrm{al}^{21}$ have shown that the functional rs6265 polymorphism in $B D N F$ is not associated with migraine in a German population. Similar to the two studies by Sutherland et $\mathrm{al}^{12}$ in an Australian population and Lemos et $\mathrm{al}^{22}$ in a Spanish cohort, they found no evidence of rs6265 in $B D N F$ as a risk factor for migraine, nor the migraine subtypes MO or MA. Moreover, they found that rs2049046 polymorphism, which resides at the $5^{\prime}$ end of one of the $B D N F$ transcripts, may be associated with migraine. However, we did not detect any association between rs2049046 polymorphism and migraine in our cohort. The rs6265 (c.196G/A) polymorphism is the most extensively studied SNP in the $B D N F$ gene. This polymorphism results in the substitution of a valine (Val) amino acid for a methionine (Met) amino acid residue at position 66 (p.Val66Met) that is known to affect the function of the protein. The polymorphism modifies the intracellular packaging of pro-BDNF and impacts on activity-dependent secretion of mature BDNF. ${ }^{25}$ The rs6265 is within the pro-protein region of $B D N F$ and affects the level of mature proteins. Thus, we found a slightly higher prevalence of the Met allele (minor A allele) in the BDNF gene in migraine patients in our Turkish population. This result indicated that there is a borderline association between the rs6265*A allele and migraine $(P=0.49)$, and this should be considered cautiously. Our current finding must be confirmed by future studies performed with larger samples.

The NGF gene is located on chromosome 1p13.1, spanning approximately $52.3 \mathrm{~kb}$ and including three exons. ${ }^{17}$ It was associated with peripheral nociception, primarily in inflammation, acting in TRPV1 activation. ${ }^{26}$ The TRPV1 receptor conducts pain sensation to the trigeminal nucleus caudalis via the trigeminal ganglion, which implies possible contribution of the TRPV1 receptor to migraine headache. ${ }^{27}$ In the literature, there is a limited number of studies evaluating the relationship between $N G F$ concentration and migraine. Sarchielli et al ${ }^{28}$ found increased $N G F$ levels in cerebrospinal fluid in patients with chronic migraine, but this finding was not specific for migraine, as it was also reported in primary fibromyalgia syndrome. Blandini et $\mathrm{al}^{11}$ showed that a significant reduction was observed in platelet $N G F$ levels of MA and MO patients compared with healthy controls. $N G F$ variants may regulate mood and therapeutic response through modulating neuroplasticity. A nonsynonymous polymorphism of the $N G F$ gene, rs6330 (c.104C $>$ T, GCC $>$ GTC, p.Ala35Val), leads to an alanine-to-valine substitution at amino acid position 35 and is suggested to influence the intracellular processing and secretion of the NGF protein. ${ }^{17}$ Also, Zakharyan et al ${ }^{16}$ demonstrated that the rs6330 genotypes affected the plasma levels of NGF. It has also been shown that the rs6330 SNP is associated with a response to cognitive behavioral therapy in pediatric patients with anxiety disorders, executive dysfunction in patients with Alzheimer's disease, affective disorders, and schizophrenia. ${ }^{16,18,29}$ However, a study of the association between migraine and the rs6330 polymorphism in the $N G F$ gene was for the first time performed in the present study. We found significant association with NGF rs6330 polymorphism and MA. The aura is an integral feature of the migraine attack in this subset of patients, but the nature of this phenomenon and its role in migraine pathophysiology remain incompletely understood. CSD is a slowly propagating wave of neuronal and glial depolarization that can activate trigeminal nociceptors in brain tissue, and it is most probably the underlying mechanism of aura. ${ }^{30}$ Upregulation of neurotrophic cascades has been previously associated with CSD. ${ }^{31}$ Furthermore, the genes of some neurotrophins have been found to be differentially expressed after CSD in the rat cortex, such as the $B D N F$ gene and the neurotrophic tyrosine kinase receptor gene. ${ }^{32}$ Our findings suggest that an important member of the neurotrophin family is $N G F$, which could be involved in pathogenesis in the aura component of MA. We suggest that there is also a need for studies to clarify the importance of the $N G F$ in aura pathophysiology.

This report has several limitations, such as a small sample size. The statistical power of the comparison of genotypes and allele frequencies among groups was below 0.78. All these statistical powers were calculated according to the obtained results. The second limitation is the imbalance in the number of patients with MA and MO in the patient group. Third, we did not measure serum levels of BDNF and NGF in the case and control groups. Finally, a limited number of polymorphisms in the $N G F$ and $B D N F$ genes was genotyped in the present study.

In conclusion, this is the first clinical study to evaluate the association between $B D N F$ and $N G F$ polymorphisms in migraine patients compared to those of healthy controls. We found that the minor T allele of rs6330 in NGF was significantly associated with MA in a Turkish case-control 
population. Our findings indicate that the NGF rs6330*T allele could play a potential role in susceptibility to aura in migraine disease. Larger sample examinations across various ethnic groups will further clarify the role of polymorphisms in $B D N F$ and $N G F$ in the etiology of migraine disease.

\section{Acknowledgment}

This research article is supported by Dicle University Scientific Research Projects Coordination Office (DUBAP, Project no: 14-TF-106).

\section{Disclosure}

The authors report no conflicts of interest in this work.

\section{References}

1. Bose P, Goadsby PJ. The migraine postdrome. Curr Opin Neurol. 2016;29(3):299-301.

2. Esposito M, Roccella M, Gallai B, et al. Maternal personality profile of children affected by migraine. Neuropsychiatr Dis Treat. 2013;9: 1351-1358.

3. Esposito M, Pascotto A, Gallai B, et al. Can headache impair intellectual abilities in children? An observational study. Neuropsychiatr Dis Treat. 2012;8:509-513.

4. Headache Classification Committee of the International Headache Society. The international classification of headache disorders, (beta version). Cephalalgia. 2013;33(9):629-808.

5. Pietrobon D, Moskowitz MA. Pathophysiology of migraine. Ann Rev Physiol. 2013;75:365-391.

6. Ho TW, Edvinsson L, Goadsby PJ. CGRP and its receptors provide new insights into migraine pathophysiology. Nat Rev Neurol. 2010; 6(10):573-582.

7. CoSkun S, Yucel Y, Cim A, et al. Contribution of polymorphisms in ESR1, ESR2, FSHR, CYP19A1, SHBG, and NRIP1 genes to migraine susceptibility in Turkish population. J Genet. 2016;95(1):131-140.

8. Mannion RJ, Costigan M, Decosterd I, et al. Neurotrophins: peripherally and centrally acting modulators of tactile stimulus-induced inflammatory pain hypersensitivity. Proc Natl Acad Sci U S A. 1999; 96(16):9385-9390.

9. Maisonpierre PC, Belluscio L, Friedman B, et al. NT-3, BDNF, and NGF in the developing rat nervous system: parallel as well as reciprocal patterns of expression. Neuron. 1990;5(4):501-509

10. Martins LB, DuarteH,FerreiraAV, RochaNP, Teixeira AL, Domingues RB. Migraine is associated with altered levels of neurotrophins. Neurosci Lett. 2015;587:6-10.

11. Blandini F, Rinaldi L, Tassorelli C, et al. Peripheral levels of BDNF and NGF in primary headaches. Cephalalgia. 2006;26(2):136-142.

12. Sutherland HG, Maher BH, Rodriguez-Acevedo AJ, Haupt LM, Griffiths LR. Investigation of brain-derived neurotrophic factor (BDNF) gene variants in migraine. Headache. 2014;54(7):1184-1193.

13. Cirulli F, Alleva E. The NGF saga: from animal models of psychosocial stress to stress-related psychopathology. Front Neuroendocrinol. 2009;30(3):379-395.

Neuropsychiatric Disease and Treatment

\section{Publish your work in this journal}

Neuropsychiatric Disease and Treatment is an international, peerreviewed journal of clinical therapeutics and pharmacology focusing on concise rapid reporting of clinical or pre-clinical studies on a range of neuropsychiatric and neurological disorders. This journal is indexed on PubMed Central, the 'PsycINFO' database and CAS,
14. Yeh YW, Kuo SC, Chen CY, et al. Harm avoidance involved in mediating the association between nerve growth factor (NGF) gene polymorphisms and antidepressant efficacy in patients with major depressive disorder. J Affect Disord. 2015;183:187-194.

15. Shu XQ, Mendell LM. Neurotrophins and hyperalgesia. Proc Natl Acad Sci US A. 1999;96(14):7693-7696.

16. Zakharyan R, Atshemyan S, Gevorgyan A, Boyajyan A. Nerve growth factor and its receptor in schizophrenia. BBA Clin. 2014;1:24-29.

17. Syed Z, Dudbridge F, Kent L. An investigation of the neurotrophic factor genes GDNF, NGF, and NT3 in susceptibility to ADHD. Am J Med Genet B Neuropsychiatr Genet. 2007;144B(3):375-378.

18. Lester KJ, Hudson JL, Tropeano M, et al. Neurotrophic gene polymorphisms and response to psychological therapy. Transl Psychiatry. 2012;2:e108.

19. Kocabas NA, Antonijevic I, Faghel C, et al. Brain-derived neurotrophic factor gene polymorphisms: influence on treatment response phenotypes of major depressive disorder. Int Clin Psychopharmacol. 2011;26(1):1-10.

20. Honea RA, Cruchaga C, Perea RD, et al. Characterizing the role of brain derived neurotrophic factor genetic variation in Alzheimer's disease neurodegeneration. PLoS One. 2013;8(9):e76001.

21. Marziniak M, Herzog AL, Mossner R, Sommer C. Investigation of the functional brain-derived neurotrophic factor gene variant Val66MET in migraine. J Neural Transm (Vienna). 2008;115(9):1321-1325.

22. Lemos C, Mendonca D, Pereira-Monteiro J, et al. BDNF and CGRP interaction: implications in migraine susceptibility. Cephalalgia. 2010; 30(11):1375-1382.

23. Faul F, Erdfelder E, Lang AG, Buchner A. G* Power 3: a flexible statistical power analysis program for the social, behavioral, and biomedical sciences. Behav Res Methods. 2007;39(2):175-191.

24. Fischer M, Wille G, Klien S, et al. Brain-derived neurotrophic factor in primary headaches. J Headache Pain. 2012;13(6):469-475.

25. Egan MF, Kojima M, Callicott JH, et al. The BDNF val66met polymorphism affects activity-dependent secretion of BDNF and human memory and hippocampal function. Cell. 2003;112(2):257-269.

26. Amaya F, Shimosato G, Nagano M, et al. NGF and GDNF differentially regulate TRPV1 expression that contributes to development of inflammatory thermal hyperalgesia. Eur J Neurosci. 2004;20(9):2303-2310.

27. Shimizu T, Shibata M, Suzuki N. [Migraine: advances in the pathophysiology and treatment]. Rinsho Shinkeigaku. 2011;51(2):103-109. Japanese.

28. Sarchielli P, Mancini ML, Floridi A, et al. Increased levels of neurotrophins are not specific for chronic migraine: evidence from primary fibromyalgia syndrome. J Pain. 2007;8(9):737-745.

29. Di Maria E, Giorgio E, Uliana V, et al. Possible influence of a nonsynonymous polymorphism located in the NGF precursor on susceptibility to late-onset Alzheimer's disease and mild cognitive impairment. J Alzheimers Dis. 2012;29(3):699-705.

30. Charles A, Brennan K. Cortical spreading depression-new insights and persistent questions. Cephalalgia. 2009;29(10):1115-1124.

31. Rangel YM, Karikó K, Harris VA, Duvall ME, Welsh FA. Dosedependent induction of mRNAs encoding brain-derived neurotrophic factor and heat-shock protein-72 after cortical spreading depression in the rat. Brain Res Mol Brain Res. 2001;88(1-2):103-112.

32. Urbach A, Bruehl C, Witte OW. Microarray-based long-term detection of genes differentially expressed after cortical spreading depression. Eur J Neurosci. 2006;24(3):841-856.

\section{Dovepress}

and is the official journal of The International Neuropsychiatric Association (INA). The manuscript management system is completely online and includes a very quick and fair peer-review system, which is all easy to use. Visit http://www.dovepress.com/testimonials.php to read real quotes from published authors. 